\title{
Mother-Child and Father-Child Relationships in Emerging Adults from Divorced and Non-Divorced Families
}

\author{
Klara Smith-Etxeberria * and Amaia Eceiza
}

check for updates

Citation: Smith-Etxeberria, Klara, and Amaia Eceiza. 2021.

Mother-Child and Father-Child Relationships in Emerging Adults from Divorced and Non-Divorced Families. Social Sciences 10: 382. https://doi.org/10.3390/socsci10100382

Academic Editor: Nigel Parton

Received: 17 August 2021

Accepted: 6 October 2021

Published: 13 October 2021

Publisher's Note: MDPI stays neutral with regard to jurisdictional claims in published maps and institutional affiliations.

Copyright: (c) 2021 by the authors. Licensee MDPI, Basel, Switzerland. This article is an open access article distributed under the terms and conditions of the Creative Commons Attribution (CC BY) license (https:/ / creativecommons.org/licenses/by/ $4.0 /)$.
Department of Basic Psychological Processes and Their Development, University of the Basque Country, 20018 San Sebatian, Spain; amaia.eceiza@ehu.eus

* Correspondence: klara.smith@ehu.eus

\begin{abstract}
The main aim of this study was to analyze the associations between parental divorce and interparental conflict with the quality of parent-child relationships. Specifically, we analyzed trust, communication and alienation in both father-child and mother-child relationships in a sample of 1078 Spanish emerging adults from divorced and non-divorced families. The interaction between parental divorce and conflict was also analyzed. In support of our expectations, parental divorce was associated with lower trust and communication, along with higher alienation in father-child and mother-child relationships. When interparental conflict was included, parental conflict was more strongly associated with lower trust and communication in mother-child relationships, and higher alienation in both mother-child and father-child relationships. However, parental divorce was still associated with low trust and communication with fathers, when interparental conflict and the interaction between parental divorce and conflict were added. In summation, our results suggest that both parental divorce and conflict should be taken into account in the study of the consequences of family-related stress variables on adult children's wellbeing. These findings add to the current literature and contribute to better comprehend the effects of parental divorce and conflict on both mother-child and father-child affective relationships in an understudied cultural context. The implications, limitations and future research recommendations are discussed.
\end{abstract}

Keywords: divorce; interparental conflict; parent-child relationships; children of divorce; emerging adulthood

\section{Introduction}

Divorce is one of the most stressful life events, bringing several emotional, affective, and social consequences for the divorcing couple and their children (Garrido-Rojas et al. 2021). Many studies have documented the short-term effects of parental divorce on children and adolescents, such as internalizing and externalizing behavior problems, lower academic achievement, poor physical health, higher risk for mental health, or attachment insecurity (Afifi and McManus 2010; Altenhofen et al. 2010; Baert and Van der Straeten 2021; Weaver and Schofield 2015). In the long term, a great body of research also suggests that parental divorce is associated with negative outcomes on adult children, such as lower educational and occupational attainment (Larson and Halfon 2013), lower wellbeing (Amato 2001; Huurre et al. 2006), insecure attachment styles (Fraley and Heffernan 2013), poor marital quality (Amato 2001), higher divorce rates (Amato 2001), mental and physical health problems (Schaan et al. 2019; Tullius et al. 2021), and less secure parent-child relationships (Amato 2001; Cui and Fincham 2010; Feeney and Monin 2016). Nevertheless, in Spain the effects of parental divorce on children and adults have been less widely examined than in other countries (e.g., Cantón et al. 2002).

In Spain, divorce was legally recognized in 1981. Since then, divorce rates have increased dramatically, from 0.6 annual divorces per 1000 inhabitants in 1990 to 2.0 per 1000 inhabitants in 2018 (Eurostat, Statistical Office of the European Communities 2020). According to the Spanish National Statistics Institute (INE 2020), 56.7\% of Spanish divorced 
families have underage children or economically dependent overage children. Parental divorce, therefore, might be a stressful life event for many Spanish young adults. Since the examination of the possible long-term effects of parental divorce on Spanish emerging adult children is limited, in this study, we attempted to fill this gap in the literature by analyzing the effects of parental divorce on parent-child relationships among emerging adults from a cultural context where divorce is still novel. Emerging adulthood has specific features that cannot be considered an extension of adolescence. Unlike emerging adults, adolescents still live with their parents, and they are minors under the law (Arnett 2015). Additionally, during adolescence, parents play a crucial role as socializing agents (Queiroz et al. 2020). Conversely, emerging adulthood is characterized by much more freedom from parental control, greater independent exploration, and greater emotional autonomy toward parents. In addition, parental socialization strategies during this developmental period are characterized by more warmth and less strictness (García et al. 2020). Even if some scholars suggest that parental socialization is over when the adolescent reaches adult age (Gimenez-Serrano et al. 2021; García et al. 2020), parents are still important figures in the transition to this period, as young adults still depend on their parents not only as an economic resource but also for emotional support and advice (Arnett 2015). Moreover, this developmental period provides an excellent opportunity for personal growth in several domains, such as education, employment, intimate relationships, and parenthood, but it is also a developmentally challenging transition to adulthood, in which relationships with parents are emotionally charged from positive emotions, such as love, gratitude, and acceptance to more negative emotions, such as resentment, disillusionment, and wariness (Arnett 2015). Given that divorce is an emotionally stressful and complex transition for families and that emerging adulthood is a stage of crisis, in this study, we expected less positive parent-child relationships among Spanish emerging adults who have experienced parental divorce.

From the divorce-stress-adjustment perspective, divorce is considered a family transition event that brings some family readjustments to its members (Amato 2010). Thus, from this perspective, it is not divorce per se that leads to negative consequences, but family life changes and stressful circumstances surrounding divorce that might increase the risk of a variety of problems among children. These circumstances refer to pre- and post-divorce conflict levels, poorer relationship quality with the custodial parent, lower frequency of contact with the non-custodial parent (Bastaits et al. 2012; Carlson 2006), lower economic resources, and other stressful events, such as changing residence, or parents remarrying (Amato 1994). Moreover, this perspective highlights that divorce is a process in which several factors may moderate children's reactions to divorce and that stressors related to this experience might mediate the association between parental divorce and children's reactions to it, leading to negative consequences that can persist into adulthood. Specifically, stressful circumstances surrounding the divorce experience might diminish parents' responsiveness and availability as primary caregivers (Feeney and Monin 2016), which can lead children to suffer from a deterioration in parenting from both custodial and non-custodial parents (Hetherington and Kelly 2002). Indeed, attachment theory suggests that early caregiving experiences influence social and close relationships throughout the life span (Bowlby 1969). Furthermore, negative family experiences, such as divorce, can affect parents' appraisals, emotions, and behaviors, leading them to be less sensitive to their children's needs which in turn, may have a negative impact on the quality of parent-child relationships. In fact, some empirical studies have associated parental divorce with less secure parent-child relationships, even in the long term, during young adulthood (Amato 2001; Feeney and Monin 2016).

The quality of parent-child relationships has also been studied as a key mediator between parental divorce and children's later adjustment, due to the modifications that parent-child relationships experience in the post-divorce period (Amato 2000; Amato and Sobolewski 2001; Lee 2019). Adult children of divorce usually have less contact with their parents, exchange less emotional support and help behaviors with them, and describe 
the relationships with their parents in a more negative way which, in turn, has been associated with lower wellbeing levels in young adulthood (e.g., Amato and Sobolewski 2001). Furthermore, according to some longitudinal studies, stressful life events, such as parental divorce, might change parent-child attachment relationships, which, in turn, may influence adult children's romantic attachment and romantic relationship quality (Lee 2019; Waters et al. 2000). A less positive involvement from parents following divorce might also reduce children's social competence and may lead adult children to hold more negative expectations towards intimate relationships (Bartell 2006; Kelly and Emery 2003).

Although some studies have exclusively examined the impact of parental divorce on parent-child relationships (e.g., Booth and Amato 2001), little is known about the potential roles that the parent's gender plays. That is, scarce studies have examined the differential effects of parental divorce on father-child and mother-child relationships (Lee 2018, 2019; Smith-Etxeberria and Eceiza 2021). A number of studies have suggested that divorce seems to affect more negatively adult children's relationships with their father than with their mother (Amato 2014; Amato and Booth 1996; King 2002). In the post-divorce period, children usually suffer from a loss of or diminished contact with their non-custodial parent, who is usually the father. That is, after parental divorce, non-custodial fathers are likely to have less contact with their children, and the frequency of contact declines over time (Carlson 2006). This situation might lead children to have a negative view of their fathers and to a decrease in closeness in the relationship with their father (Bartell 2006; Kelly and Emery 2003; Lee 2019). These changes in father-child relationships might also be associated with young adults' lower wellbeing, more negative relationship attitudes, lower romantic relationship quality, and higher risk for psychopathology (Bartell 2006; Carr et al. 2018; Kelly and Emery 2003; Reuven-Krispin et al. 2021). In fact, both partial and complete father absence during the post-divorce period have been associated with lower wellbeing levels among young adults (Reuven-Krispin et al. 2021).

Regarding mother-child relationships, some studies have not found negative effects of parental divorce (Lee 2019). Moreover, the literature review suggests that adult children of divorce seem to have a more secure attachment relationship with their mother than with their father (Carranza et al. 2009; Fraley and Heffernan 2013; Hannum and Dvorak 2004). Indeed, a few studies have even found that adult children of divorce report more affective quality, independence and emotional support with their mothers than children from non-divorced families (Riggio 2004; Riggio and Valenzuela 2011). However, a few studies have still suggested that parental divorce is negatively associated with mother-child relationships due to interparental conflict and disrupted parenting (Beelmann and SchmidtDenter 2009; Cooney et al. 1995; Wallerstein et al. 2013) and that maternal sensitivity is lower in mother-child dyads in divorced families compared to non-divorced families (Sutherland et al. 2012). That is, stressors associated with the process of divorce, such as emotional vulnerability or a decline in economic resources, might diminish the custodial parent's (usually the mother) parenting quality (Hetherington and Kelly 2002; Riggio and Valenzuela 2011). Hence, children may also experience less positive involvement from their mother (Kelly and Emery 2003).

Given the inconsistent results regarding the effects of parental divorce on father-child and mother-child relationships, more empirical research is needed to clarify this issue, especially in young adulthood, analyzing which variables associated with the quality of father-child and mother-child relationships are more affected. Some scholars (e.g., Armsden and Greenberg 1987) have defined the quality of parent-child affective relationships in terms of trust (i.e., parental understanding, respect and mutual trust), communication (i.e., extent and quality of verbal communication with parents), and alienation (i.e., feelings of alienation and loneliness in parent-child relationships). Thus, in the current study, we analyzed the association between parental divorce and trust, communication, and alienation in mother-child and father-child relationships during young adulthood.

In addition to parental divorce, continued exposure to parental conflict has also been associated with negative outcomes in both mother-child and father-child relationships 
during young adulthood (Riggio 2004; Riggio and Valenzuela 2011), such as lower affective quality, independence, and emotional support in both father-child and mother-child relationships (Riggio 2004). The spillover hypothesis in the family systems theory suggests that negativity from disruption in one family subsystem (e.g., interparental conflict) might spill over into other subsystems (e.g., parent-child relationships), such that parents might reproduce marital hostility and aggressiveness in the relationships with their children (Harold and Sellers 2018; Sturge-Apple et al. 2006). Parental stress related to conflict might hinder parents' ability to be sensitive and supportive attachment figures to their children. Moreover, parental conflict throughout early development might lead children to view themselves as unlovable and unworthy of love, while they might perceive others as undependable and uncaring and as a consequence, close interpersonal relationships as undependable and transitory (Belsky et al. 1991; Steinberg et al. 2006). Continued marital conflict, therefore, might also be associated with more negative parent-child interactions in childhood, adolescence, and young adulthood (Martin et al. 2017; Sturge-Apple et al. 2006). In this vein, the results of some studies have indicated that adult children who report high levels of interparental conflict show more insecure attachment relationships with both parents (Hannum and Dvorak 2004; Ross and Fuertes 2010). In addition, perceived frequency, intensity, and resolution of interparental conflict, along with both perceived threat and self-blame in the presence of interparental conflict, have been associated with lower trust and communication in parent-child relationships (Ross and Fuertes 2010).

Empirical research has also shown that parent-child relationship quality mediates the association between parental conflict and adult children's adjustment. Indeed, children exposed to parental conflict show feelings of keeping a less close relationship with both parents (Booth and Amato 1994; Sobolewski and Amato 2007) which in turn, has been linked with a greater risk of adult children suffering from distress, lower self-esteem, general unhappiness, and lower romantic relationship quality (Booth and Amato 2001; Cusimano and Riggs 2013). Likewise, children exposed to parental conflict show higher parent-child alienation (Monè and Biringen 2006) and a higher likelihood of feeling caught between parents which in turn, leads to lower wellbeing of children (Amato and Afifi 2006).

Some studies have also compared the effects of parental divorce with those of interparental conflict. Overall, both parental conflict and divorce are associated with more negative parent-child relationships (Amato and Booth 1996; Booth and Amato 1994). However, Monè and Biringen (2006), for example, found that interparental conflict is associated with greater alienation in parent-child relationships, regardless of parental divorce. Children whose parents have a highly conflicted marriage are more likely to feel caught in the middle between their parents than those from divorced families (Amato and Afifi 2006). Other investigations, instead, have suggested differential effects of parental divorce and conflict for the quality of mother-child and father-child relationships. Specifically, when comparing the effects of parental divorce and interparental conflict, a few studies have concluded that parental divorce leads to more negative father-child relationships, whereas interparental conflict is linked with more negative mother-child and father-child relationships (Hannum and Dvorak 2004; Riggio 2004; Riggio and Valenzuela 2011; SmithEtxeberria and Eceiza 2021). In order to shed further light on this issue, in this study, we also examined the association between parental divorce and conflict with young adult children's trust, communication, and alienation in both father-child and mother-child affective relationships.

In the study of the effects of these family experiences, beyond comparing and analyzing the differential effects of parental divorce and conflict, it is necessary to analyze their interactive relationship. The stress-relief hypothesis (Wheaton 1990) posits that divorce, as a stressful life experience, can benefit children if perceived as a way of escape from a stressful or dysfunctional environment. That is, parental divorce might alleviate the stress derived from high levels of interparental conflict, leading young adult children to fare better when the parental marital relationship is characterized by high levels of conflict 
in the pre-divorce period, whereas they fare worse when low parental conflict precedes divorce (Booth and Amato 2001). Evidence suggests that parental divorce might have a buffering effect on the negative effects of conflictive interactions between parents on children and that high levels of parental conflict might lead to even more negative outcomes for children when parents do not divorce (Gager et al. 2016). Some researchers have attempted to test this hypothesis by analyzing the interaction between parental divorce and conflict. Although several studies have failed to find an interactive effect on parentchild relationship quality (Booth and Amato 2001; Monè and Biringen 2006; Riggio 2004; Riggio and Valenzuela 2011), a recent study found such an interactive effect (Yu et al. 2010), suggesting that divorce uniquely moderates the negative effects of interparental conflict on mother-daughter relationships. That is, Yu et al. (2010) found that interparental conflict in non-divorced families has a negative impact on mother-daughter relationships and that this effect is reduced when parents divorce, such that parental divorce seems to have a buffering effect on mother-daughter relationships when the parental marital relationship is characterized by high levels of conflict. However, these previous studies did not analyze the difference between destructive and constructive conflict behaviors. Destructive conflict behaviors are characterized by the cultivation of hostility in the relationship and a lack of resolution, whereas constructive behaviors are characterized by cooperation, resolution, problem solving, and support, which are associated with more positive outcomes in children (Kopystynska et al. 2020; McCoy et al. 2013). Therefore, in this study, in order to test the stress-relief hypothesis, we analyzed the interaction between parental divorce and low and high interparental conflict by distinguishing between that which was unresolved and resolved. The literature review suggests that the resolution of conflictive behaviors between parents plays a primary role in children's adjustment. Furthermore, offspring who perceive a lack of resolution within their parental marital relationships show poor adjustment, whereas those who observe resolution strategies in their interparental disagreements are more likely to be better adjusted (Cantón et al. 2013). Hence, in this study, we expected poorer parent-child relationships among emerging adult children who perceive frequent, intense, and non-resolved conflictive interactions between their parents. By contrast, we predict positive outcomes in parent-child relationships among those who perceive both frequent and intense but resolved interparental conflict, as well as low levels of frequency and intensity and high levels of resolution in their interparental interactions.

\section{Overview of the Current Study}

By investigating the role that parental divorce and interparental conflict play in young adult children's affective relationships quality with their parents, we aimed to contribute to the literature in several ways. First, limited attention has been given to the study of the associations between parental divorce and conflict and their interactive effect on parent-child relationships. Moreover, the potential roles of parents' gender have not been extensively investigated. Thus, in this study we attempted to contribute to the literature by analyzing these effects on both father-child and mother-child relationship quality, considering the different dimensions that define the quality of father-child and mother-child affective relationships, such as trust, communication, and alienation. Next, although the literature review suggests that constructive or resolved conflictive interactions between parents might lead to positive outcomes in children, this link has not been widely empirically examined. Finally, the study of these effects in Spanish emerging adults is limited. Herein, the following hypotheses were tested:

1. Parental divorce will be associated with lower trust and communication and higher alienation in mother-child and father-child relationships.

2. High unresolved interparental conflict will be associated with lower trust and communication and higher alienation in mother-child and father-child relationships.

3. High unresolved interparental conflict will be more strongly associated with lower trust and communication and higher alienation in mother-child and father-child relationship quality than parental divorce. 
4. High resolved parental conflict will be associated with higher trust and communication and lower alienation in both father-child and mother-child affective relationships quality.

5. High interparental conflict and parental divorce will interact to explain both fatherchild and mother-child affective relationships, such that parental divorce will moderate the effects of high parental conflict. Specifically, for young adults from nondivorced families, high interparental conflict will be positively associated with lower trust and communication and higher alienation in mother-child and father-child relationship quality to a greater degree than for young adults whose parents divorced.

\section{Method}

\subsection{Participants and Procedure}

Participants were undergraduate and vocational training school students from the Autonomous Community of the Basque Country (Spain). The study subjects were informed in class about the main goals of the study and signed a consent form before completing the measures. This study was approved by the Ethics Committee in Human Research at the University of the Basque Country (ethical approval CODE: CEISH/153/2012/SMITH ECHEBARRIA). Of the 1106 participants, 28 cases were dropped for both not completing the measures and not meeting the requirement of being emerging adults (between 18 and 30 years of age). The final sample consisted of 1078 Spanish emerging adults. $48.5 \%$ $(n=523)$ of the respondents were undergraduate students (psychology: 15.7\%; education: $11.3 \%$; criminology: $3.9 \%$; engineering: $15.9 \%$; business administration: $1.7 \%$ ), whereas $51.5 \%(n=555)$ of the respondents were vocational training school students. The average age of the respondents was 21.4 years $(S D=3)$. Of the participants, $50.5 \%$ were women and $16 \%$ had experienced parental divorce. The mean age at the time of divorce was 10.83 years, and $72.8 \%$ of mothers were the custodial parent.

\subsection{Measures}

Independent variables: Interparental conflict was assessed through the adapted Spanish version (Iraurgi et al. 2008) of the Children's Perception of Interparental Conflict Scale (Grych et al. 1992). Participants who had experienced parental divorce were requested to report on parental conflict during the pre-divorce period. The following sub-scales of interparental conflict were assessed: Perceived Frequency (four items, e.g., "My parents hardly ever argued or disagreed"), Intensity (four items, e.g., "My parents tended to get really angry when they argued or disagreed"), and Resolution (four items, e.g., "When my parents argued, they usually worked things out"). Each item had three possible responses: $0=$ true, $1=$ sort of true, and $2=$ false. $\alpha$ for each subscale was $0.84,0.70$, and 0.78 , respectively. In this study, a confirmatory factor analysis (CFA) confirmed the three-factor structure proposed by this scale's authors. The fit indices for the CFA were $\chi^{2}(49)=387.27$, $p<0.001, \mathrm{RMSEA}=0.083, \mathrm{NNFI}=0.97, \mathrm{CFI}=0.97$, and SRMR $=0.051$. In addition, in order to test some of our hypotheses, three conflict groups were created through a cluster analysis: (1) High unresolved interparental conflict ( $n=265$; adult children who reported frequent, intense, and unresolved parental conflict); (2) high resolved interparental conflict $(n=393$; emerging adults reporting on frequent and intense, but resolved conflict between their parents); (3) low interparental conflict ( $n=380$; those who reported non-frequent, non-intense, and resolved parental conflict). Parental divorce was assessed by asking participants whether their parents were separated or divorced $(1=$ divorced; $0=$ not divorced).

Dependent variables: Parent-child relationships quality was assessed with the mother and father subscales of the Inventory of Parent and Peer Attachment (IPPA; Armsden and Greenberg 1987). This measure assesses adolescents' and young adults' perceptions of the positive and negative affective/cognitive dimensions of relationships with each parent. Each of these subscales consists of three factors: Trust (nine items, e.g., "My mother/father respects my feeling"), Communication (nine items, e.g., "I tell my mother/father about my 
problems and troubles"), and Alienation (seven items, e.g., "I get upset easily around my mother/father"). Responses to each item ranged from 1 (almost never or never true) to 5 (almost always or always true). The fit indices for the mother subscale were $\chi^{2}(249)=1711.91$, $p<0.001, \mathrm{RMSEA}=0.081, \mathrm{NNFI}=0.96, \mathrm{CFI}=0.96$, and SRMR $=0.056$. Meanwhile, in the father subscale the fit indices were $\chi^{2}(249)=2091.28, p<0.001$, RMSEA $=0.095, \mathrm{NNFI}=0.96$, $\mathrm{CFI}=0.96$, and SRMR $=0.064$. The $\alpha$ coefficients for each factor in the mother-child and father-child scales are shown in Table 1.

Table 1. Descriptive information about the study variables.

\begin{tabular}{lcccc}
\hline \multicolumn{1}{c}{ Constructs } & Indicators & M (SD) or $n$ & Range & $\alpha$ \\
\hline \multirow{3}{*}{ Parental divorce } & No & 905 & - & - \\
\cline { 2 - 5 } & Yes & 173 & - & - \\
\hline \multirow{3}{*}{ Interparental Conflict } & Frequency & $0.60(0.62)$ & $0-2$ & 0.84 \\
\cline { 2 - 5 } & Intensity & $1.38(0.44)$ & $0-2$ & 0.70 \\
\cline { 2 - 5 } & Resolution & $1.44(0.51)$ & $0-2$ & 0.78 \\
\hline \multirow{3}{*}{ Mother-child relationship } & Trust & $4.19(0.72)$ & $1-5$ & 0.90 \\
\cline { 2 - 5 } & Communication & $3.72(0.79)$ & $1-5$ & 0.86 \\
\cline { 2 - 5 } Father-child relationship & Alienation & $2.35(0.72)$ & $1-5$ & 0.67 \\
\cline { 2 - 5 } & Trust & $3.97(0.84)$ & $1-5$ & 0.92 \\
\cline { 2 - 5 } & Communication & $3.17(0.89)$ & $1-5$ & 0.89 \\
\cline { 2 - 5 } & Alienation & $2.50(0.78)$ & $1-5$ & 0.71 \\
\hline
\end{tabular}

Covariates. Age, gender $(1=$ male; $0=$ female), relationship status (relationship $=1$; single $=0$ ) and both parents' socioeconomic status (SES), as measured by their current occupation (entrepreneurs or managers = high SES; professionals = medium-high SES; middle managers or technicians = medium SES; factory workers = medium-low SES; housework = low SES) were added as control variables in the regression models.

\subsection{Data Analysis Plan}

IBM SPSS 24 was used for statistical analyses. A set of hierarchical multiple regressions were run on trust, communication, and alienation in both mother-child and father-child relationships in order to test the predictive ability of parental divorce and interparental conflict, as well as their interactive effect. To compare emerging adults from divorced families with those from non-divorced families, parental divorce and control variables were entered in Model 1. Model 2 also included both high-resolved and high-unresolved interparental conflict. In Model 3, two-way interactions between parental divorce and interparental conflict were added. Significant interactions were plotted using the worksheets developed by Dawson (2014). The $+1 S D$ and $-1 S D$ levels of the moderator and independent variables were used. Simple slope $t$-tests for two-way significant interactions were also calculated (Dawson 2014).

\section{Results}

\subsection{Descriptive and Bivariate Analyses}

Table 1 provides descriptive information about the study variables.

In Table 2, we present bivariate correlations. Parental divorce was associated with lower trust and communication with both the mother and father and positively with alienation in father-child relationships. Perceived frequency and intensity of interparental conflict were associated with lower trust and communication with both the mother and father and higher alienation in both mother-child and father-child relationships. Perceived resolution in interparental conflict correlated positively with trust and communication in 
both mother-child and father-child relationships, whereas it correlated negatively with alienation in mother-child and father-child relationships.

Table 2. Correlations among the study variables.

\begin{tabular}{|c|c|c|c|c|c|c|c|c|c|c|}
\hline & 1 & 2 & 3 & 4 & 5 & 6 & 7 & 8 & 9 & 10 \\
\hline 1. Divorce & 1 & & & & & & & & & \\
\hline 2. Freq & $0.27^{* *}$ & 1 & & & & & & & & \\
\hline 3. Intens & $0.21 * *$ & $0.67 * *$ & 1 & & & & & & & \\
\hline 4. Resol & $-0.37^{* *}$ & $-0.57^{* *}$ & $-0.47^{* *}$ & 1 & & & & & & \\
\hline 5. TrustMoth & $-0.10^{* *}$ & $-0.31^{* *}$ & $-0.20^{* *}$ & $0.31 * *$ & 1 & & & & & \\
\hline 6. ComMoth & $-0.08^{* *}$ & $-0.21^{* *}$ & $-0.11^{* *}$ & $0.26 * *$ & $0.73^{* *}$ & 1 & & & & \\
\hline 7. AliMoth & 0.05 & $0.29 * *$ & $0.20 * *$ & $-0.24^{* *}$ & $-0.62 * *$ & $-0.58^{* *}$ & 1 & & & \\
\hline 8. TrustFath & $-0.27^{* *}$ & $-0.38^{* *}$ & $-0.27^{* *}$ & $0.40^{* *}$ & $0.38^{* *}$ & $0.29 * *$ & $-0.29 * *$ & 1 & & \\
\hline 9. ComFath & $-0.19^{* *}$ & $-0.28^{* *}$ & $-0.22 * *$ & $0.36 * *$ & $0.27^{* *}$ & $0.37^{* *}$ & $-0.29 * *$ & $0.76^{* *}$ & 1 & \\
\hline 10. AliFath & $0.12 * *$ & $0.36^{* *}$ & $0.29 * *$ & $-0.28^{* *}$ & $-0.16^{* *}$ & $-0.19^{* *}$ & $0.45^{* *}$ & $-0.58^{* *}$ & $-0.60^{* *}$ & 1 \\
\hline
\end{tabular}

Note. Divorce, parental divorce; Freq, frequency of interparental conflict; Intens, intensity of interparental conflict; Resol, resolution of interparental conflict; TrustMoth, trust in mother; ComMoth, communication with mother; AliMoth, alienation in the relationship with mother; TrustFath, trust in Father; ComFath, communication with Father; AliFath, alienation in the relationship with father; ${ }^{* *} p<0.01$.

\subsection{Hierarchical Multiple Regression Analyses}

\subsubsection{Mother-Child Relationships Quality}

Results on trust in mother-child relationships are presented in Table 3.

Table 3. Summary of the hierarchical multiple regressions for the variables predicting trust in mother-child relationships.

\begin{tabular}{|c|c|c|c|c|c|c|c|c|c|}
\hline \multirow[b]{2}{*}{ Variable } & \multicolumn{3}{|c|}{ Model 1} & \multicolumn{3}{|c|}{ Model 2} & \multicolumn{3}{|c|}{ Model 3} \\
\hline & $B$ & $S E B$ & $\beta$ & $B$ & $S E B$ & $\beta$ & $B$ & $S E B$ & $\beta$ \\
\hline \multicolumn{10}{|l|}{ Control variables } \\
\hline \multicolumn{10}{|l|}{ Explanatory variables } \\
\hline Parental divorce & $-0.209 * * *$ & 0.064 & -0.107 & -0.046 & 0.064 & -0.024 & -0.024 & 0.153 & -0.012 \\
\hline High resolved conflict & & & & $-0.165^{* * *}$ & 0.049 & -0.115 & $-0.17^{* * *}$ & 0.052 & -0.124 \\
\hline High unresolved conflict & & & & $-0.532 * * *$ & 0.058 & -0.333 & $-0.502^{* * *}$ & 0.063 & -0.314 \\
\hline \multicolumn{10}{|l|}{ Interactions } \\
\hline Divorce $\times$ high resolved & & & & & & & 0.093 & 0.186 & 0.028 \\
\hline Divorce $\times$ high unresolved & & & & & & & -0.115 & 0.178 & -0.045 \\
\hline$R^{2}$ & & 0.027 & & & 106 & & & 0.109 & \\
\hline$F$ for change in $R^{2}$ & & $2.632 * *$ & & & $92 * * *$ & & & 1.141 & \\
\hline
\end{tabular}

As expected, parental divorce was associated with lower trust in mother-child relationships (Table 3; Model 1). When both high resolved and high unresolved interparental conflict was added (Model 2), parental divorce was no longer significant, and both high unresolved and high resolved interparental conflict were negatively associated with trust in mother-child relationships. These effects remained, even when interactions between parental divorce and interparental conflict were added (Model 3).

Parental divorce was associated with lower communication with the mother (Table 4; Model 1). However, when both interparental conflict levels were included (Model 2), parental divorce was no longer significant. In this model, high resolved and high unresolved parental conflicts were associated with lower communication in mother-child relationships. By adding interactions between parental divorce and interparental conflict (Model 3), a significant interaction was found for parental divorce $\times$ high resolved interparental conflict, after controlling for all other variables in the model. 
Table 4. Summary of the hierarchical multiple regressions for the variables predicting communication in mother-child relationships.

\begin{tabular}{|c|c|c|c|c|c|c|c|c|c|}
\hline \multirow[b]{2}{*}{ Variable } & \multicolumn{3}{|c|}{ Model 1} & \multicolumn{3}{|c|}{ Model 2} & \multicolumn{3}{|c|}{ Model 3} \\
\hline & $B$ & $S E B$ & $\beta$ & $B$ & $S E B$ & $\beta$ & $B$ & $S E B$ & $\beta$ \\
\hline \multicolumn{10}{|l|}{ Control variables } \\
\hline \multicolumn{10}{|l|}{ Explanatory variables } \\
\hline Parental divorce & $-0.213^{* *}$ & 0.071 & -0.096 & -0.084 & 0.072 & -0.038 & -.0279 & 0.174 & -0.126 \\
\hline High resolved conflict & & & & $-0.156^{* *}$ & 0.056 & -0.096 & $-0.197^{* * *}$ & 0.059 & -0.121 \\
\hline High unresolved conflict & & & & $-0.427 * * *$ & 0.066 & -0.236 & $-0.404^{* * *}$ & 0.071 & -0.224 \\
\hline \multicolumn{10}{|l|}{ Interactions } \\
\hline Divorce $\times$ high resolved & & & & & & & $0.434^{*}$ & 0.211 & 0.117 \\
\hline Divorce $\times$ high unresolved & & & & & & & 0.087 & 0.202 & 0.030 \\
\hline$R^{2}$ & & 0.060 & & & 100 & & & 0.106 & \\
\hline$F$ for change in $R^{2}$ & & $6.187^{* * *}$ & & & $35^{* * *}$ & & & $3.202 *$ & \\
\hline
\end{tabular}

The results from the slope difference tests (see Figure 1) showed that young adults from non-divorced families score higher on mother-child communication when the level of conflict between parents is low than when the level of conflict between parents is highresolved $(t=-3.53, p<0.001)$. No significant differences were found among those from divorced families, such that the level of communication with the mother remained the same, regardless of the level of conflict between parents. In addition, no significant differences were found among those reporting low levels of conflict, nor among those reporting high resolved conflict between their parents, irrespective of parental divorce $(p>0.10)$.

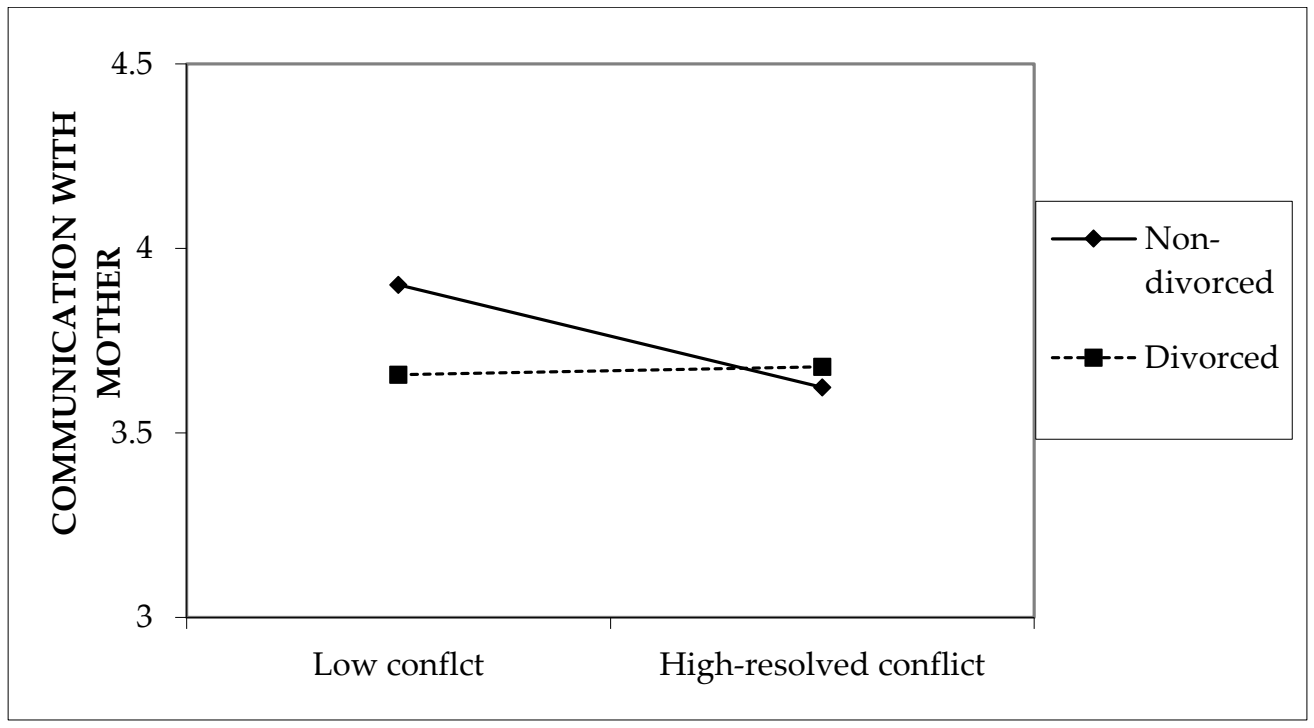

Figure 1. Interaction plot for the significant two-way interaction between parental divorce and high resolved interparental conflict on communication in mother-child relationships.

Parental divorce was associated with higher alienation in mother-child affective relationships (Table 5; Model 1). Again, when both interparental conflict levels were added (Model 2), parental divorce was no longer significant and both high resolved and high unresolved parental conflict were positively associated with mother-child alienation, even when interactions between parental divorce and interparental conflict were added (Model 3). 
Table 5. Summary of the hierarchical multiple regressions for the variables predicting alienation in mother-child relationships.

\begin{tabular}{|c|c|c|c|c|c|c|c|c|c|}
\hline \multirow[b]{2}{*}{ Variable } & \multicolumn{3}{|c|}{ Model 1} & \multicolumn{3}{|c|}{ Model 2} & \multicolumn{3}{|c|}{ Model 3} \\
\hline & $B$ & $S E B$ & $\beta$ & $B$ & $S E B$ & $\beta$ & $B$ & $S E B$ & $\beta$ \\
\hline \multicolumn{10}{|l|}{ Control variables } \\
\hline \multicolumn{10}{|l|}{ Explanatory variables } \\
\hline Parental divorce & $0.156^{*}$ & 0.066 & 0.077 & -0.003 & 0.066 & -0.001 & -0.100 & 0.159 & -0.050 \\
\hline High resolved conflict & & & & $0.247^{* * *}$ & 0.051 & 0.168 & $0.247^{* * *}$ & 0.053 & 0.168 \\
\hline High unresolved conflict & & & & $0.537^{* * *}$ & 0.060 & 0.328 & $0.512^{* * *}$ & 0.065 & 0.312 \\
\hline \multicolumn{10}{|l|}{ Interactions } \\
\hline Divorce $\times$ high resolved & & & & & & & 0.059 & 0.192 & 0.018 \\
\hline Divorce $\times$ high unresolved & & & & & & & 0.161 & 0.184 & 0.061 \\
\hline$R^{2}$ & & 0.015 & & & 093 & & & 0.094 & \\
\hline$F$ for change in $R^{2}$ & & 1.505 & & & $45^{* * *}$ & & & 0.483 & \\
\hline
\end{tabular}

\subsubsection{Father-Child Relationships Quality}

Table 6 shows the results on trust in father-child affective relationship quality. In support of our expectation, parental divorce was negatively associated with trust in father-child relationships. When both high resolved and high unresolved interparental conflict were added (Model 2), parental divorce and both interparental conflict levels were associated with lower trust in the father. The interaction terms between parental divorce and both high levels of interparental conflict (resolved and unresolved) did not yield significant effects (Model 3).

Table 6. Summary of the hierarchical multiple regressions for the variables predicting trust in father-child relationships.

\begin{tabular}{|c|c|c|c|c|c|c|c|c|c|}
\hline \multirow[b]{2}{*}{ Variable } & \multicolumn{3}{|c|}{ Model 1} & \multicolumn{3}{|c|}{ Model 2} & \multicolumn{3}{|c|}{ Model 3} \\
\hline & $B$ & $S E B$ & $\beta$ & $B$ & $S E B$ & $\beta$ & $B$ & $S E B$ & $\beta$ \\
\hline \multicolumn{10}{|l|}{ Control variables } \\
\hline \multicolumn{10}{|l|}{ Explanatory variables } \\
\hline Parental divorce & $-0.605^{* * *}$ & 0.074 & -0.257 & $-0.381^{* * *}$ & 0.073 & -0.162 & $-0.340 *$ & 0.174 & -0.144 \\
\hline High resolved conflict & & & & $-0.257^{* * *}$ & 0.056 & -0.150 & $-0.252^{* * *}$ & 0.059 & -0.147 \\
\hline High unresolved conflict & & & & $-0.741^{* * *}$ & 0.066 & -0.389 & $-0.739 * * *$ & 0.072 & -0.388 \\
\hline \multicolumn{10}{|l|}{ Interactions } \\
\hline Divorce $\times$ high resolved & & & & & & & -0.062 & 0.212 & -0.016 \\
\hline Divorce $\times$ high unresolved & & & & & & & -0.040 & 0.202 & -0.013 \\
\hline$R^{2}$ & & 0.081 & & & 190 & & & 0.190 & \\
\hline$F$ for change in $R^{2}$ & & $8.474^{* * *}$ & & & $85^{* * *}$ & & & 0.042 & \\
\hline
\end{tabular}

$$
{ }^{*} p<0.05 ;{ }^{* * *} p<0.001 \text {. }
$$

As shown in Table 7, we found similar results to those found in father-child trust for communication in father-child relationships. That is, parental divorce (Model 1) and both high resolved and high unresolved parental conflict (Model 2) are associated with lower communication with the father, even when interactions between parental divorce and conflict were included (Model 3). 
Table 7. Summary of the hierarchical multiple regressions for the variables predicting communication in father-child relationships.

\begin{tabular}{|c|c|c|c|c|c|c|c|c|c|}
\hline \multirow[b]{2}{*}{ Variable } & \multicolumn{3}{|c|}{ Model 1} & \multicolumn{3}{|c|}{ Model 2} & \multicolumn{3}{|c|}{ Model 3} \\
\hline & $B$ & $S E B$ & $\beta$ & $B$ & $S E B$ & $\beta$ & $B$ & $S E B$ & $\beta$ \\
\hline \multicolumn{10}{|l|}{ Control variables } \\
\hline \multicolumn{10}{|l|}{ Explanatory variables } \\
\hline Parental divorce & $-0.509 * * *$ & 0.081 & -0.202 & $-0.304^{* * *}$ & 0.081 & -0.121 & $-0.591 * *$ & 0.193 & -0.235 \\
\hline High resolved conflict & & & & $-0.309 * * *$ & 0.062 & -0.1699 & $-0.318^{* * *}$ & 0.065 & -0.174 \\
\hline High unresolved conflict & & & & $-0.689^{* * *}$ & 0.073 & -0.338 & $-0.750 * * *$ & 0.079 & -0.368 \\
\hline \multicolumn{10}{|l|}{ Interactions } \\
\hline Divorce $\times$ high resolved & & & & & & & 0.231 & 0.235 & 0.054 \\
\hline Divorce $\times$ high unresolved & & & & & & & $0.430^{+}$ & 0.224 & 0.131 \\
\hline$R^{2}$ & & 0.046 & & & 128 & & & 0.132 & \\
\hline$F$ for change in $R^{2}$ & & $4.631^{* * *}$ & & & $68^{* * *}$ & & & 1.973 & \\
\hline
\end{tabular}

In Table 8, we present the results on alienation in father-child relationships. Parental divorce was associated with higher alienation in father-child relationships (Table 8; Model 1). However, when both interparental conflict levels were added (Model 2), parental divorce was no longer associated with higher father-child alienation, and both high resolved and high unresolved parental conflict was positively associated with father-child alienation, even when interaction terms between parental divorce and conflict were added (Model 3).

Table 8. Summary of the hierarchical multiple regressions for the variables predicting alienation in father-child relationships.

\begin{tabular}{|c|c|c|c|c|c|c|c|c|c|}
\hline \multirow[b]{2}{*}{ Variable } & \multicolumn{3}{|c|}{ Model 1} & \multicolumn{3}{|c|}{ Model 2} & \multicolumn{3}{|c|}{ Model 3} \\
\hline & $B$ & $S E B$ & $\beta$ & $B$ & $S E B$ & $\beta$ & $B$ & $S E B$ & $\beta$ \\
\hline \multicolumn{10}{|l|}{ Control variables } \\
\hline \multicolumn{10}{|l|}{ Explanatory variables } \\
\hline Parental divorce & $0.314^{* * *}$ & 0.072 & 0.141 & 0.103 & 0.071 & 0.046 & $0.311^{+}$ & 0.169 & 0.140 \\
\hline High resolved conflict & & & & $0.353^{* * *}$ & 0.054 & 0.219 & $0.375^{* * *}$ & 0.057 & 0.233 \\
\hline High unresolved conflict & & & & $0.723 * * *$ & 0.064 & 0.403 & $0.738^{* * *}$ & 0.069 & 0.411 \\
\hline \multicolumn{10}{|l|}{ Interactions } \\
\hline Divorce $\times$ high resolved & & & & & & & -0.294 & 0.205 & -0.079 \\
\hline Divorce $\times$ high unresolved & & & & & & & -0.219 & 0.196 & -0.075 \\
\hline$R^{2}$ & & 0.023 & & & 142 & & & 0.144 & \\
\hline$F$ for change in $R^{2}$ & & $2.291 *$ & & & $09 * * *$ & & & 1.038 & \\
\hline
\end{tabular}

\section{Discussion}

The present study analyzed the associations between parental divorce and interparental conflict with trust, communication, and alienation in both mother-child and father-child relationship quality in a Spanish young adult sample. In addition, the interactive effect of parental divorce and conflict was also tested. This study makes important contributions in relation to other studies by (1) Analyzing a non-widely studied developmental period; (2) examining an understudied population of Spanish emerging adults; (3) studying simultaneously the associations between parental divorce and both high resolved and high unresolved interparental conflict with trust, communication, and alienation in mother-child and father-child relationships and (4) examining the interactive effect between parental divorce and both high resolved and high unresolved interparental conflict.

Parental divorce is a life event stressor that involves multiple changes and has significant consequences for children. Even though several studies have found stronger effects on children during the first years after parental divorce, some other studies have found long-term consequences on young adult children (e.g., Hetherington and Kelly 2002). In 
this investigation, as expected (hypothesis 1), our results suggested that adult children of divorce show lower relationship quality with both parents (Amato 2001; Sobolewski and Amato 2007). Specifically, parental divorce was associated with lower trust and communication, along with higher alienation, in both mother-child and father-child relationships. Stressors associated with the divorce process are usually accompanied by deterioration in the parenting of both custodial and non-custodial parents. Custodial parents (usually mothers) might be less sensitive to their children's needs and non-custodial parents might diminish their parenting role during the divorce process and the post-divorce period (Hetherington and Kelly 2002). All of these changes may negatively affect parent-child relationship quality, even in the long term, when children are young adults and are entering a new important developmental stage, as shown by our results. However, our findings suggest a stronger association between parental divorce and qualities related to father-child relationships, such as lower trust and communication. This result is consistent with several investigations that indicate that father-child relationships are more deteriorated than mother-child relationships by the divorce experience (Lee 2019; Riggio and Valenzuela 2011; Smith-Etxeberria and Eceiza 2021). This might be due to the fact that the parenting of fathers is more likely to be negatively affected by circumstances surrounding the divorce experience (Lee 2019), whereas mothers' parenting roles do not seem to be so altered. Non-custodial fathers usually have little contact with their children, and this contact decreases over time. This has an impact on the quality of their involvement in their children's lives, which, in turn, also affects negatively both children's wellbeing and the quality of father-child relationships, even until adulthood (Lee 2019; Reuven-Krispin et al. 2021).

Another way through which parent-child relationships can be affected in adulthood is through continued exposure to high levels of conflictive interactions between parents. In fact, research on the associations between interparental conflict and parent-child relationship quality indicates negative and significant associations between high levels of parental conflict and both mother-child and father-child relationship quality (Riggio 2004; Smith-Etxeberria and Eceiza 2021). That is, continued exposure to parental conflict might hinder parents' ability to function as a secure base and safe haven for their children, due to the stress related to conflictive interactions (Martin et al. 2017). This lower sensitivity might also explain more negative parent-child interactions in young adulthood (Davies and Cummings 2006). In our study, parental conflict is associated with more negative father-child and mother-child relationships in young adulthood. Overall, in support of our second hypothesis, our results suggest that interparental conflict is associated with lower trust and communication and higher alienation in the relationship quality with both parents. Furthermore, our findings support our predictions (hypothesis 3 ) about the greater predictive ability of parental conflict than parental divorce on parent-child relationships in young adulthood. However, this conclusion is especially meaningful for trust, communication, and alienation in mother-child relationships and for alienation in father-child relationships. That is, when both high resolved and high unresolved levels of interparental conflict were included, parental divorce was no longer associated with dimensions defining the quality of mother-child relationships (trust, communication, and alienation) and alienation in father-child relationships. Nevertheless, our results suggest that both parental divorce and conflict are concurrently associated with lower trust and communication in father-child relationships. Therefore, our findings confirm the detrimental effects of divorce mainly on father-child relationships, as parental divorce is negatively associated with lower trust and communication in father-child relationships, even when parental conflict is taken into account. Thus, in agreement with other studies, parental conflict is associated with more negative mother-child and father-child relationship quality, whereas parental divorce is more strongly associated with negative father-child relationships (e.g., Riggio and Valenzuela 2011). Our findings also suggest that when adult children observe frequent, intense, and both resolved and unresolved conflicts between parents, they report lower trust, communication, and alienation in the relationship with both parents. Thus, observing 
frequent and intense conflictive interactions between parents, regardless of being resolved or not, would be equally negatively influential, given that, in both cases, adult children report lower trust and communication along with higher alienation in the relationship with both parents. This does not confirm our expectations regarding the positive effect of high resolved interparental conflict (hypothesis 4).

In addition, the results of this study indicate that parental divorce moderates the effects of high resolved interparental conflict on mother-child communication (hypothesis 5). Specifically, adult children from non-divorced families whose parents remained in a high conflict marriage showed lower communication with their mother than when the level of conflict between their parents was low. Conversely, among young adult children from divorced families, higher levels of conflict in the parental marital relationship were not associated with lower communication in mother-child relationships, such that the level of mother-child communication remained the same regardless of interparental conflict. These results would support the stress-relief hypothesis (Wheaton 1990), which suggests that parental divorce might relieve the stress derived from continued exposure to high levels of parental conflict. That is, parental divorce might be a protective factor for motherchild communication under adverse circumstances, such as high parental conflict. This is consistent with the study conducted by Yu et al. (2010), who concluded that parental divorce has a buffering effect on mother-daughter relationships when the interparental relationship is characterized by high levels of conflict. However, in agreement with other studies, and contrary to what we expected, our findings did not suggest such significant interaction for the other variables that define the quality of father-child and mother-child relationships (e.g., Riggio 2004). Therefore, our expectations regarding the interactive effect between parental divorce and conflict were partially confirmed.

\section{Study Limitations, Strengths and Implications}

Our results should be seen in the light of several limitations. First, this study had a retrospective and cross-sectional design. This makes it difficult to infer causal conclusions, as adult children of divorce reported on parental conflict prior to divorce. Emerging adults might have provided information about past interparental relationships based on their current life stress or current post-divorce interparental relationships. Thus, participants may not be able to recall accurately past parental relationships. Some other investigations have used prospective longitudinal data to enhance the reliability of measures (e.g., Lee 2019). Therefore, future studies should focus on conducting a longitudinal follow-up design study with a Spanish population, in order to precisely control the actual pre-divorce parental conflict level, by also analyzing interparental conflict from parents' perspective. In addition, in our study, we uniquely analyzed college and vocational school students. Given the age range of our sample, future studies should replicate this investigation with a broader and more heterogeneous sample. Next, parental divorce was assessed as a dichotomous variable by asking participants whether their parents were divorced or separated. Divorce is a diverse experience, and several circumstances surrounding the divorce process might explain better children's reactions to divorce (e.g., YárnozYaben and Garmendia 2015). Besides, parental divorce does not always affect parentchild relationships to the same degree. That is, several factors surrounding the divorce experience, such as contact and closeness with non-custodial parents, type of custody (e.g., shared or sole custody), parents' distress and adjustment following divorce, the amount of interparental conflict, or diminished financial resources might better explain the effects than divorce per se (Amato 2010; Kelly and Emery 2003). Thus, future studies should focus on the examination of other variables related to the divorce process, in order to detect factors that might explain variations in the effects of parental divorce on parent-child relationship quality. A final limitation has to do with not examining protective factors, such as authoritative parenting, both parents' psychological wellbeing, parents' effective co-parenting relationship in the post-divorce period, or children's individual characteristics, such as their effective coping skills or psychosocial maturity. Analyzing these variables 
might help explain a reduced effect of both parental divorce and conflict (Amato 2014; DeBoard-Lucas et al. 2010; Kelly and Emery 2003; Lee 2018; Rejaäan et al. 2021; Yeung 2021). Moreover, the study of these factors could be of use to gather important information in order to make preventive and clinical intervention efforts to reduce the negative effects of both parental divorce and conflict.

Despite the limitations of this study, it contributes to the investigation of emerging adults' father-child and mother-child relationship quality in several ways. First, the associations between parental divorce and both high resolved and high unresolved interparental conflict with trust, communication, and alienation in mother-child and father-child relationships were analyzed by testing simultaneously their effect in a non-widely studied sample and cultural context. Another important contribution refers to the study of the role of parents' gender, as many studies have not focused on the differential effects of parental divorce and conflict on mother-child and father-child relationships separately. In addition, this study analyzed the interaction between parental divorce and conflict in order to examine the moderating role of parental divorce in mother-child and fatherchild relationships. Overall, our findings contribute to better understanding the effects of parental divorce on parent-child relationships during emerging adulthood, and add to the existing literature, suggesting that interparental conflict is more strongly associated with both mother-child and father-child relationship quality in young adulthood more so than parental divorce. In addition, parental divorce is more strongly related to lower father-child relationship quality than to mother-child relationship quality. Thus, our results highlight the long-term consequences of parental divorce and conflict and suggest the importance of analyzing more factors (e.g., child's gender and age at time of divorce) in order to extend our knowledge about the way through which these stressful family experiences might shape emerging adult children's relationships with their parents.

These findings have implications for public policies and preventive interventions for divorced and non-divorced families with dysfunctional family dynamics. Parental stress related to dysfunctional family dynamics derived from conflictive interactions between parents might diminish parents' sensitivity, responsiveness, and warmth toward their children's needs, which may have detrimental effects on parent-child relationship quality, even during emerging adulthood. Thus, more efforts should be made to implement and design psychosocial prevention programs aimed at strengthening parental relationships, along with improving parental sensitivity through attachment-based interventions (Berlin et al. 2016). In addition, although in the current study, parental divorce was negatively associated with both mother-child and father-child relationship quality, emerging adult children's current perceptions of the relationship with their father seemed to be more damaged. Therefore, intervention programs focused on improving children's adjustment to divorce should provide tools to enhance father-child relationships.

Author Contributions: Conceptualization K.S.-E. and A.E.; methodology, K.S.-E.; validation, K.S.-E. and A.E.; formal analysis, K.S.-E.; investigation, K.S.-E.; resources, A.E.; data curation, K.S.-E. and A.E.; writing—original draft preparation, K.S.-E.; writing—review and editing, K.S.-E. and A.E.; supervision, A.E.; project administration, K.S.-E.; funding acquisition, K.S.-E. All authors have read and agreed to the published version of the manuscript.

Funding: This research was funded by the department of Education, Universities and Research of the Basque Government, grant number BFI-2011-74.

Institutional Review Board Statement: This study was approved by the Ethics Committee in Human Research at the University of the Basque Country (ethical approval CODE: CEISH/153/2012/SMITH ECHEBARRIA).

Informed Consent Statement: Informed consent was obtained from all subjects involved in the study.

Data Availability Statement: The data presented in this study are available on request from the corresponding author. 
Conflicts of Interest: The authors declare no conflict of interest.

\section{References}

Afifi, Tamara D., and Tara McManus. 2010. Divorce disclosures and adolescents' physical and mental health and parental relationship quality. Journal of Divorce and Remarriage 21: 83-107. [CrossRef]

Altenhofen, Shannon, Katie Sutherland, and Zeynep Biringen. 2010. Families experiencing divorce: Age at onset of overnight stays, conflict, and emotional availabitlity as predictors of child attachment. Journal of Divorce and Remarriage 51: 141-56. [CrossRef]

Amato, Paul R. 1994. Father-children relations, mother-children relations, and offspring psychological well-being in early adulthood. Journal of Marriage and the Family 56: 1031-42. [CrossRef]

Amato, Paul R. 2000. The consequences of divorce for adults and children. Journal of Marriage and the Family 62: 1269-87. [CrossRef]

Amato, Paul R. 2001. Children of divorce in the 1990s: An update of the Amato and Keith (1991) meta-analysis. Journal of Family Psychology 15: 355-70. [CrossRef]

Amato, Paul R. 2010. Research on divorce: Continuing trends and new developments. Journal of Marriage and Family 72: 650-66. [CrossRef]

Amato, Paul R. 2014. The consequences of divorce for adults and children: An update. Društvena Istraživanja 23: 5-24. [CrossRef]

Amato, Paul R., and Tamara D. Afifi. 2006. Feeling caught between parents: Adult children's relations with parents and subjective well-being. Journal of Marriage and Family 68: 222-35. [CrossRef]

Amato, Paul R., and Alan Booth. 1996. A prospective study of divorce and parent-child relationships. Journal of Marriage and the Family 58: 356-65. [CrossRef]

Amato, Paul R., and Juliana M. Sobolewski. 2001. The effects of divorce and marital discord on adult children's psychological well-being. American Sociological Review 66: 900-21. [CrossRef]

Armsden, Gay C., and Mark T. Greenberg. 1987. The Inventory of Parent and Peer Attachment: Relationships to well-being in adolescence. Journal of Youth and Adolescence 16: 427-54. [CrossRef]

Arnett, Jeffrey J. 2015. Emerging Adulthood: The Winding Road from the Late Teens through the Twenties. New York: Oxford University Press.

Baert, Stijn, and Greet Van der Straeten. 2021. Secondary school success in times of parental divorce. Family Relations 70: 575-86. [CrossRef]

Bartell, Denise S. 2006. Influence of parental divorce on romantic relationships in young adulthood: A cognitive-developmental perspective. In Handbook of Divorce and Relationship Dissolution. Edited by Mark A. Fine and John H. Harvey. New York: Taylor and Francis Group, LLC, pp. 339-60.

Bastaits, Kim, Koen Ponner, and Dimitri Mortelmans. 2012. Parenting of divorced fathers and the association with children's self-esteem. Journal of Youth and Adolescence 41: 1643-56. [CrossRef]

Beelmann, Wolfgang, and Ulrich Schmidt-Denter. 2009. Mother-child interaction following marital separation: A longitudinal observation study. European Psychologist 14: 307-31. [CrossRef]

Belsky, Jay, Lawrence Steinberg, and Patricia Draper. 1991. Childhood experience, interpersonal development, and reproductive strategy: An evolutionary theory of socialization. Child Development 62: 647-70. [CrossRef] [PubMed]

Berlin, Lisa J., Charles H. Zeanah, and Alicia F. Lieberman. 2016. Prevention and Intervention Programs to Support Early Attachment Security: A Move to the Level of the Community. In Handbook of Attachment: Theory, Research and Applications. Edited by Jude Cassidy and Philip R. Shaver. New York: The Guilford Press, pp. 739-58.

Booth, Alan, and Paul R. Amato. 1994. Parental marital quality, parental divorce, and relations with parents. Journal of Marriage and the Family 56: 21-34. [CrossRef]

Booth, Alan, and Paul R. Amato. 2001. Parental predivorce relations and offspring postdivorce well-being. Journal of Marriage and Family 63: 197-212. [CrossRef]

Bowlby, John. 1969. Attachment and Loss: Attachment. New York: Basic Books, vol. I.

Cantón, José, María Rosario Cortés, and María Dolores Justicia. 2002. Las consecuencias del divorcio en los hijos [The consequences of divorce on children]. Psicopatología Clínica, Legal y Forense 2: 47-66.

Cantón, José, María Rosario Cortés, María Dolores Justicia, and David Cantón. 2013. Violencia doméstica, divorcio y adaptación psicológica: De la disarmonía familiar al desarrollo de los hijos [Domestic Violence, Divorce and Psychological Adjustment: From Family Disharmony to Children's Development]. Madrid: Pirámide.

Carlson, Marcia J. 2006. Family structure, father involvement, and adolescent behavioral outcomes. Journal of Marriage and Family 68 : 137-54. [CrossRef]

Carr, Colleen M., Sharlene A. Wolschik, Jenn-Yun Tein, and Irwin Sandler. 2018. Mother-Adolescent and Father-Adolescent Relationships After Divorce: Relations with Emerging Adults' Romantic Attachment. Journal of Divorce and Remarriage 60: 194-210. [CrossRef] [PubMed]

Carranza, Laura V., Peter R. Kilmann, and Jennifer M. C. Vendemia. 2009. Links between parent characteristics and attachment variables for college students of parental divorce. Adolescence 44: 253-71. [PubMed]

Cooney, Teresa M., M. Katherine Hutchinson, and Diane M. Leather. 1995. Surviving the breakup: Predictors of parent-adult child relations after parental divorce. Family Relations 44: 153-61. [CrossRef] 
Cui, Ming, and Frank D. Fincham. 2010. The differential effects of parental divorce and marital conflict on young adult romantic relationships. Personal Relationships 17: 331-43. [CrossRef]

Cusimano, Angela M., and Shelley A. Riggs. 2013. Perceptions of interparental conflict, romantic attachment, and psychological distress in college students. Couple and Family Psychology: Research and Practice 2: 45-59. [CrossRef]

Davies, Patrick T., and Mark Cummings. 2006. Interparental discord, family process, and developmental psychopathology. In Developmental Psychopathology: Risk, Disorder and Adaptation. Edited by Dante Cicchetti and Donald Cohen. Hoboken: John Wiley and Sons, Inc., vol. III, pp. 86-128.

Dawson, Jeremy F. 2014. Moderation in management research: What, why, when and how. Journal of Business Psychology 29: 1-19. [CrossRef]

DeBoard-Lucas, Renee L., Gregory M. Fosco, Sarah R. Raynor, and John H. Grych. 2010. Interparental conflict in context: Exploring relations between parenting processes and children's conflict appraisals. Journal of Clinical Child and Adolescent Psychology 39: 163-75. [CrossRef]

Eurostat, Statistical Office of the European Communities. 2020. Marriage and Divorce Statistics. Available online: https:/ / ec.europa.eu/ eurostat/statistics-explained/index.php?title=Marriage_and_divorce_statistics\#Fewer_marriages.2C_more_divorces (accessed on 9 July 2021).

Feeney, Brooke C., and Joan K. Monin. 2016. Divorce through the lens of attachment theory. In Handbook of Attachment: Theory, Research and Applications. Edited by Jude Cassidy and Philip R. Shaver. New York: The Guilford Press, pp. 941-65.

Fraley, R. Chris, and Marie E. Heffernan. 2013. Attachment and parental divorce: A test of the diffusion and sensitive period hypotheses. Personality and Social Psychology Bulletin 39: 1199-213. [CrossRef]

Gager, Constance T., Scott T. Yabiku, and Miriam R. Linver. 2016. Conflict or divorce? Does parental conflict and/or divorce increase the likelihood of adult children's cohabiting and marital dissolution? Marriage and Family Review 52: 243-61. [CrossRef]

García, Oscar F., Maria C. Fuentes, Enrique Gracia, Emilia Serra, and Fernando Garcia. 2020. Parenting warmth and strictness across three generations: Parenting styles and psychosocial adjustment. International Journal of Environmental Research and Public Health 17: 7487. [CrossRef] [PubMed]

Garrido-Rojas, Lusmenia, Mónica Guzmán-González, Rodolfo Mendoza-Llanos, Diana Ribera-Ottenberger, and Paula Contreras-Garay. 2021. Emotional regulation and depression in a sample of separated and divorced Chilean adults. Current Psychology 40: 1767-78. [CrossRef]

Gimenez-Serrano, Sofia, Fernando Garcia, and Oscar F. Garcia. 2021. Parenting styles and its relations with personal and social adjustment beyond adolescence: Is the current evidence enough? European Journal of Developmental Psychology. [CrossRef]

Grych, John H., Michael Seid, and Frank D. Fincham. 1992. Assessing marital conflict from the child's perspective: The Children's Perception of Interparental Conflict Scale. Child Development 63: 558-72. [CrossRef] [PubMed]

Hannum, James W., and Dawn M. Dvorak. 2004. Effects of family conflict, divorce, and attachment patterns on the psychological distress and social adjustment of college freshmen. Journal of College Student Development 45: 27-42. [CrossRef]

Harold, Gordon T., and Ruth Sellers. 2018. Annual Research Review: Interparental conflict and youth psychopathology: An evidence review and practice focused update. Journal of Child Psychology and Psychiatry 59: 374-402. [CrossRef]

Hetherington, E. Mavis, and John Kelly. 2002. For Better or for Worse: Divorce Reconsidered. New York: Norton.

Huurre, Taina, Hanna Junkkari, and Hillevi y Aro. 2006. Long-term psychosocial effects of parental divorce. European Archives of Psychiatry and Clinical Neuroscience 256: 256-63. [CrossRef] [PubMed]

Instituto Nacional de Estadística (National Statistics Institute) (INE). 2020. Estadística de Nulidades, Separaciones y Divorcios Año 2019. (Statistics on Nulities, Separations and Divorces 2019). Available online: https: / / www.ine.es/dyngs/INEbase/es/operacion. htm?c=Estadistica_C\&cid=1254736176798\&menu=ultiDatos\&idp=1254735573206 (accessed on 9 July 2021).

Iraurgi, Ioseba, Ana Martínez-Pampliega, Mireya Sanz, Leire Cosgaya, Edurne Galíndez, and Ana Muñoz. 2008. Escala de Conflicto Interparental de los Hijos (CPIC): Estudio de validación de una versión abreviada de 36 ítems. [Children's Perception of Interparental Conflict Scales (CPIC): Validation study of a sort version of 36 items]. Revista Iberoamericana de Diagnóstico y Evaluación Psicológica 1: 9-34.

Kelly, Joan B., and Robert E. Emery. 2003. Children's adjustment following divorce: Risk and resilience perspectives. Family Relations 52: 352-62. [CrossRef]

King, Valarie. 2002. Parental divorce and interpersonal trust in adult offspring. Journal of Marriage and Family 64: 642-56. [CrossRef]

Kopystynska, Olena, Melissa A. Barnett, and Melissa A. Curran. 2020. Constructive and destructive interparental conflict, parenting, and coparenting alliance. Journal of Family Psychology 34: 414-24. [CrossRef]

Larson, Kandyce, and Neal Halfon. 2013. Parental divorce and adult longevity. International Journal of Public Health 58: 89-97. [CrossRef]

Lee, Sun-A. 2018. Parental divorce, relationships with fathers and mothers, and children's romantic relationships in young adulthood. Journal of Adult Development 25: 121-34. [CrossRef]

Lee, Sun-A. 2019. Romantic relationships in young adulthood: Parental divorce, parent-child relationships during adolescence, and gender. Journal of Child and Family Studies 28: 411-23. [CrossRef]

Martin, Meredith J., Melissa L. Sturgue-Apple, Patrick T. Davies, Christine V. Romero, and Abigail Buckholz. 2017. A process model of the implications of spillover from coparenting conflicts into the parent-child attachment relationship in adolescence. Developments and Psychopathology 29: 417-31. [CrossRef] [PubMed] 
McCoy, Kathleen P., Melissa R. W. George, E. Mark Cummings, and Patrick T. Davies. 2013. Constructive and destructive marital conflict: Parenting, and children's school and social adjustment. Social Development 22: 641-62. [CrossRef]

Monè, Jennifer Gerber, and Zeynep Biringen. 2006. Perceived parent-child alienation: Empirical assessment of parent-child relationships within divorced and intact families. Journal of Divorce and Remarriage 45: 131-56. [CrossRef]

Queiroz, Pablo, Oscar F. Garcia, Fernando Garcia, Juan J. Zacares, and Cleonice Camino. 2020. Self and nature: Parental socialization, self-esteem, and environmental values in Spanish adolescents. International Journal of Environmental Research and Public Health 17: 3732. [CrossRef] [PubMed]

Rejaäan, Zoë, Inge E. van der Valk, and Susan Branje. 2021. Postdivorce Coparenting Patterns and Relations With Adolescent Adjustment. Journal of Family Issues, 1-21. [CrossRef]

Reuven-Krispin, Hanita, Dana Lassri, Patrick Luyten, and Golan Shahar. 2021. Consequences of divorce-based father absence during childhood for young adult well-being and romantic relationships. Family Relations 70: 452-66. [CrossRef]

Riggio, Heidi R. 2004. Parental marital conflict and divorce, parent-child relationships, social support, and relationship anxiety in young adulthood. Personal Relationships 11: 99-114. [CrossRef]

Riggio, Heidi R., and Ann Marie Valenzuela. 2011. Parental marital conflict and divorce, parent-child relationships, and social support among Latino-American young adults. Personal Relationships 18: 392-409. [CrossRef]

Ross, Jennifer, and Jairo Fuertes. 2010. Parental Attachment, Interparental Conflict, and Young Adults' Emotional Adjustment. Counseling Psychologist 38: 1050-77. [CrossRef]

Schaan, Violetta K., André Schulz, Hartmut Schächinger, and Claus Vögele. 2019. Parental divorce is associated with an increased risk to develop mental disorders in women. Journal of Affective Disorders 257: 91-99. [CrossRef]

Smith-Etxeberria, Klara, and Amaia Eceiza. 2021. Parental divorce, interparental conflict, and parent-child relationships in Spanish young adults. Anales de Psicología 37: 1-9. [CrossRef]

Sobolewski, Juliana M., and Paul R. Amato. 2007. Parents' discord and divorce, parent-child relationships and subjective well-being in early adulthood: Is feeling close to two parents always better than feeling close to one? Social Forces 85: 1105-24. [CrossRef]

Steinberg, Sara J., Joanne Davila, and Frank Fincham. 2006. Adolescent marital expectations and romantic experiences: Associations with perceptions about parental conflict and adolescent attachment security. Journal of Youth and Adolescence 35: 314-29. [CrossRef]

Sturge-Apple, Melissa L., Patrick T. Davies, and E. Mark Cummings. 2006. Impact of hostility and withdrawal in interparental conflict on parental emotional unavailability and children's adjustment difficulties. Child Development 77: 1623-41. [CrossRef] [PubMed]

Sutherland, Katie E., Shannon Altenhofen, and Zeynep Biringen. 2012. Emotional availability during mother-child interactions in divorcing and intact married families. Journal of Divorce and Remarriage 53: 126-41. [CrossRef]

Tullius, Janne M., Marlou L. A. De Kroon, Josué Almansa, and Sijmen A. Reijneveld. 2021. Adolescents' mental health problems increase after parental divorce, not before, and persist until adulthood: A longitudinal TRIAl study. European Child and Adolescent Psychiatry, 1-10. [CrossRef]

Wallerstein, Judith, Julia Lewis, and Sherrin Packer Rosenthal. 2013. Mothers and their children after divorce: Report from a 25-year longitudinal study. Psychoanalitic Psychology 30: 167-84. [CrossRef]

Waters, Everett, Susan Merrick, Dominique Treboux, Judith Crowell, and Leah Albersheim. 2000. Attachment security in infancy and early adulthood: A twenty-year longitudinal study. Child Development 71: 684-89. [CrossRef]

Weaver, Jennifer, and Thomas Schofield. 2015. Mediation and moderation of divorce of divorce effects on children's behavior problems. Journal of Family Psychology 29: 39-48. [CrossRef] [PubMed]

Wheaton, Blair. 1990. Life Transitions, Role Histories, and Mental Health. American Sociological Review 55: 209-23. [CrossRef]

Yárnoz-Yaben, Sagrario, and Alaitz Garmendia. 2015. Parental divorce and emerging adults' subjective well-being: The role of "carrying messages". Journal of Child and Family Studies 25: 638-46. [CrossRef]

Yeung, Jerf W. K. 2021. Family processes, parenting practices, and psychosocial maturity of Chinese youths: A latent variable interaction and mediation analysis. International Journal of Environmental Research and Public Health 18: 4357. [CrossRef]

Yu, Tianyi, Gregory S. Pettit, Jennifer E. Lansford, Kenneth A. Dodge, and John E. Bates. 2010. The Interactive Effects of Marital Conflict and Divorce on Parent-Adult Children's Relationships. Journal of Marriage and Family 72: 282-92. [CrossRef] [PubMed] 